\title{
Points of view on lactose intolerance
}

\author{
By Leif Hambrceus
}

IN THIS ISSUE of Scand $J$ Nutr (pp 154-176) nine articles are published from the meeting Lactose intolerance revisited, February 1-2, 2001, Stockholm, Sweden. Some further subjects of special interest were discussed during the meeting, and are reviewed in this short article.

THE UNIQUENESS OF LACTOSE: Lactose occurs in nature only in mammalian milk. According to Bo Lönnerdal, Univ. of California, USA, who has performed a series of metabolic studies using breast milk and milk from the rhesus monkey, these are the most lactose-rich kind of mammalian milk, both containing around $7 \%$ lactose. They both represent supersaturated solutions of lactose, i.e. you cannot get more lactose into a water solution.

Lactose and galactose are very unusual forms of sugars with a specific binding and a result of very complicated synthesis in the mammary gland. There has to be a reason why mammalian milks contain such a complicated product. Only two species, sealions and seals, produce lactose-free milk, in which the dominating energy source is fat. If the mammary gland synthesises such a specific product as lactose it might be for the health of the offspring. Michael Golden, Univ. of Aberdeen, Scotland, argued that lactose should be considered an essential constituent and that lactose-free milk might thus even be detrimental.

There are several hypotheses for lactose being an essential nutrient. It might be difficult to obtain enough galactose for synthesis of galactose-containing substances, e.g. galactolipids, in the rapidly growing brain, as well as in cell membranes in a newborn and/or rapidly growing infant. Lactose has an impact on the gastrointestinal flora and there are also indications that lactose might have a beneficial effect on calcium absorption.

THE GENETICS OF LACTOSE INTOLERANCE: How old is the mutation resulting in lactase persistence/lactose tolerance in adults, and how could the gene be traced? Are we dealing with many different mutations, which may express themselves differently? There is a possibility that there is more than one mutation, that mutations occurred at different times, and it is of interest to get further data on the selection pressure, which seems to have been quite different in different populations, said Timo Sahi, Univ. of Helsinki. The selection mechanism might very well be different in different populations. A $1 \%$ selection power may have this kind of influence over many generations.

To what extent might different levels of residual lactase activity have something to do with milk production and consumption? According to Sahi, in certain areas where adult people do not consume milk nowadays, there were lots of cows before Christ. Others have argued that in some areas the children and even the adults with lactase persistence had a greater chance of survival if they could either suck at their mother's breast or drink cow milk. The milk consumption of ancestors over hundreds of years ago is of importance! Milk production figures in various countries are not necessarily a true indicator of the milk consumption due to import and export. Furthermore, fermented cheese are almost lactose-free, and thus their consumption cannot be used as indicators of lactose tolerance of the population.

Leif Hambræus, Professor emeritus, Uppsala University, Sweden.

Brahevägen 8B, SE-185 31 Vaxholm, E-mail: leif.hambraeus@medsci.uu.se
An anthropological approach to this question relates the residual lactase activity to the number of years that different populations have been practising cattle breeding. There was a selection of those who tolerated milk in times when little food and nutrients were available. This perhaps happened when cattle breeding spread form the south to the north, and may explain the present prevalences of hypolactasia in Europe. Golden argued that it is in hunger periods, when nothing else is available but animal products including milk, that the capacity to handle lactose is most important. It is the selection pressure under stressed, rather than normal conditions, that is essential for explaining differences in the prevalence of hypolactasia between populations.

Another interesting observation is that fermentation of milk, which leads to a reduced lactose content, is used as a preservation method in tropical climates, but the further north you move, the more fresh milk is consumed. For several centuries before Christ, people fermented milk and in this way there was a reduced risk of malabsorption and lactose intolerance.

THE CLINICAL RELEVANCE OF LACTOSE INTOLERANCE: Interestingly, quite a few of the lecturers questioned whether lactose really represented a major clinical problem. Golden argued that lactose is not a problem in developing countries and in the treatment of malnutrition. The practical implication of stressing the potential problems of lactose intolerance in the developing world has come into focus - in spite of the fact that some people have limited capacity to digest lactose, while other people have an enormous capacity for drinking milk. Malnourished people in the developing world, with low lactase activity, respond well to milk products. They do not get diarrhoea and they recover from it. In refugee camps, dry skimmed milk is often the only food available in treating malnourished people, he said.

It was stressed that milk protein allergy/intolerance, somewhat in contrast to lactose intolerance, may disappear later in life.

THE NEED FOR LACTOSE-FREE PRODUCTS: A number of lactose-reduced/lactose-free products are available on the market, both consumer milk products and clinical dietetic products. Do problems due to lactose content in formulas really occur? To avoid this question all manufacturers now produce lactose-free products, essentially for marketing reasons.

In Sweden, lactose-free means that the lactose content should be below the detection limit. Various methods may, however, have various limits, also dependent on product types. The methods have been developed so that the detection limit is now 0.01 instead of $0.1 \mathrm{~g} / 100 \mathrm{~g}$. But there are no indications or even possibilities that such low amounts of lactose can ever provoke symptoms, and therefore such low limits are hardly of any clinical significance. Rather than using a relative definition such as "below detection limit", that changes when methods are developed, an absolute level, based on the relevance for developing clinical symptoms, would be preferable. Lactose-reduced products should contain less than $1 \mathrm{~g} / 100 \mathrm{~g}$. Accordingly, low-lactose milk with at least $80 \%$ of the lactose hydrolysed, can be found on the Swedish and Finnish markets. Lactose reduced gruels are available in Sweden, but is there really a need for these products? There is a conflict for the manufacturers as it is a perceived need to have a marketing claim that the product is low-lactose or lactose-free. 